\title{
A EDUCAÇÃO FÍSICA LEGALIZADA NA EDUCAÇÃO INFANTIL EM CUIABÁ-MT: UMA ANÁLISE A PARTIR DA DANÇA ENQUANTO FERRAMENTA PEDAGÓGICA
}

\author{
Creverson Luam de Oliveira (D) 1, Cleonice Terezinha Fernandes (D) 2 \\ Rosilene Maria Tessari iD3
}

\section{Resumo}

Atualmente a Educação Física (EF) é um componente curricular obrigatório com igual relevância em relação às demais disciplinas, possuindo diversas abordagens pedagógicas possíveis para além dos consagrados esportes e lutas, como o movimento livre e a dança. Nesse contexto, surgiu o questionamento que norteou esse estudo: como a EF, com o suporte da dança, contribui com o desenvolvimento da criança na Educação Infantil? Sendo assim, esse artigo é um recorte de uma pesquisa de Mestrado, com o objetivo de analisar as contribuições da EF e seus conteúdos no desenvolvimento da criança na Educação Infantil, na perspectiva da unidade temática dança. De natureza qualitativa, a abordagem metodológica envolveu a pesquisa bibliográfica e a análise documental, em que foram apreciados documentos oficiais do Município de Cuiabá, como Leis, Diretrizes e Políticas Educacionais; Projetos Políticos Pedagógicos de Unidades Educacionais que atendem a Educação Infantil e planos de aula de professores que atuam com a disciplina. Os resultados apontam para a priorização das atividades que envolvem jogos e brincadeiras, sendo a dança mais utilizada em representações de datas comemorativas. As considerações finais destacam a necessidade de as atividades pedagógicas da EF para a Educação Infantil se pautarem mais na relação entre ambiente, cultura e conhecimento, inserindo a dança também como suporte à aprendizagem infantil, na perspectiva da interação entre movimento e expressões corporais com 0 desenvolvimento cognitivo.

Palavras-chave: Educação Física; Movimento; Dança; Metodologia

\section{LEGAL PHYSICAL EDUCATION IN EARLY CHILDHOOD EDUCATION IN CUIABÁ-MT: AN ANALYSIS FROM DANCE AS A PEDAGOGICAL TOOL}

\begin{abstract}
Currently, Physical Education (PE) is a mandatory curricular component with equal relevance in relation to other subjects, having several possible pedagogical approaches in addition to the renowned sports and fights, such as free movement and dance. In this context, the question that guided this study emerged: how does PE, with the support of

\footnotetext{
${ }^{1}$ Mestrando pelo Programa de Pós-Graduação em Ensino, da associação ampla entre o Instituto Federal de Mato Grosso (IFMT) e a Universidade de Cuiabá (UNIC). Especialista em Gestão Escolar. Licenciado em Educação Física.

2 Doutora em Ciências da Motricidade, com pós-doutorado em Conhecimento Especializado do Professor (Huelva/Espanha). Docente do Programa de Pós-Graduação em Ensino, da associação ampla IFMT-UNIC.

${ }^{3}$ Mestre em Ensino pelo Programa de Pós-Graduação em Ensino, da associação ampla entre IFMT-UNIC. Especialista em Mídias Digitais para a Educação. Licenciado em Pedagogia.
} 
dance, contribute to the development of children in Kindergarten? Therefore, this article is an excerpt from a Master's research, with the aim of analyzing the contributions of PE and its contents in the development of children in Early Childhood Education, from the perspective of the dance thematic unit. Qualitative in nature, the methodological approach involved bibliographical research and documental analysis, where official documents of the Municipality of Cuiabá were analyzed, such as Laws, Guidelines and Educational Policies; Political Pedagogical Projects of Educational Units that serve Early Childhood Education and lesson plans for teachers who work with the discipline. The results point to the prioritization of activities involving games and games, being the dance most used in representations of commemorative dates. The final considerations highlight the need for PE pedagogical activities for Early Childhood Education to be more based on the relationship between environment, culture and knowledge, including dance as a support for childhood learning, from the perspective of the interaction between movement and bodily expressions with development cognitive.

Keywords: Physical Education; Movement; Dance; Methodology

\section{Introdução}

A Constituição Federal Brasileira (BRASIL, 1988) destaca a educação básica como obrigatória e gratuita, compreendendo-a em Educação Infantil, Ensino Fundamental de nove anos e Ensino Médio. Nesse cenário, as diversas áreas do conhecimento escolar são estruturadas de modo que os estudantes consigam se desenvolver construindo competências e habilidades necessárias para conviverem em sociedade.

Sob essa perspectiva temos a Educação Física (EF), que é um componente obrigatório no currículo escolar e que apresenta tanta relevância quanto as demais disciplinas (BRASIL, 1997). Vale destacar que por meio da EF e suas diversas abordagens pedagógicas, dentre elas, o movimento e a dança, que quando sistematizadas significativamente promovem a integração corpo e mente e, consequentemente, auxiliam no processo de aprendizagem e o desenvolvimento do ser humano de forma integral em seus mais variados níveis e espaços.

O Referencial Curricular Nacional para a Educação Infantil (RCNEI) apresenta, para crianças nessa etapa da escolarização básica, o Movimento como componente curricular a ser trabalhado. Dentre os objetivos propostos para o trabalho com crianças de quatro a seis anos, relativos ao envolvimento da dança, o RCNEI (BRASIL, 1998, p. 27) destaca:

- ampliar as possibilidades expressivas do próprio movimento, utilizando gestos diversos e o ritmo corporal nas suas brincadeiras, danças, jogos e demais situações de interação;

- controlar gradualmente o próprio movimento, aperfeiçoando seus recursos de deslocamento e ajustando suas habilidades motoras para utilização em jogos, brincadeiras, danças e demais situações;

Assim, o documento considera que o movimento deve ser entendido como expressão social e/ou corporal, como um suporte ao desenvolvimento e aprendizagem da criança, destacado da seguinte maneira: 
Ao movimentar-se, as crianças expressam sentimentos, emoções e pensamentos, ampliando as possibilidades do uso significativo de gestos e posturas corporais. O movimento humano, portanto, é mais do que simples deslocamento do corpo no espaço: constitui-se em uma linguagem que permite às crianças agirem sobre o meio físico e atuarem sobre o ambiente humano, mobilizando as pessoas por meio de seu teor expressivo (BRASIL, 1998, p. 23).

No município de Cuiabá-MT as Diretrizes Municipais para a Educação ainda não aderiram ao termo Movimento como componente curricular, mantendo em sua Matriz Curricular a Educação Física como disciplina a ser desenvolvida na Educação Infantil. A importância do movimento, entretanto, é ressaltada nas políticas educacionais a partir das relações com os dispositivos legais que as embasam (RCNEI, 1998; DCNEI, 2010; BNCC, 2017). No mundo contemporâneo a escola se constituiu como local privilegiado na promoção do crescimento e desenvolvimento pessoal e social da criança, portanto quanto mais amplo o leque de vivências a ela ofertadas, mais essa socialização se tornará significativa. Nesse cenário, a Educação Infantil é um espaço de descobrimentos e de novas oportunidades que são direcionadas às crianças, com o intuito da ampliação das suas vivências individuais e coletivas, em um processo de socialização por meio de aspectos culturais, sociais e educativos diferenciados do seu espaço familiar. Nesse contexto, com a inserção da dança, há ainda maiores oportunidades de desenvolvimento dos aspectos biopsicossociais infantis.

Para isso, faz-se necessário direcionar a dança no espaço escolar associada ao movimento como suporte pedagógico, de modo que, como ferramenta de apoio possa contribuir para o aprendizado e a formação do cidadão, criando um elo mais curto e significativo entre a criança e o professor, de modo a tornar o processo educativo mais holístico, eficiente e prazeroso.

Partindo dessa concepção, emerge nessa investigação um problema norteador a ser analisado para que possamos melhor compreender tal universo: como a EF, com o suporte da dança, contribui com o desenvolvimento da criança na Educação Infantil?

Diante desse questionamento, surgiu a necessidade do delineamento de objetivos que pudessem orientar essa pesquisa. Assim, o objetivo principal desse estudo foi analisar as contribuições da EF e seus conteúdos no desenvolvimento da criança na Educação Infantil na perspectiva da unidade temática dança. Não menos importantes para essa investigação, os objetivos específicos que orientaram a pesquisa foram: i) Destacar a inclusão da EF nas escolas de Educação Infantil do município de Cuiabá a partir da Lei que determina a presença do professor de EF com Licenciatura nesta modalidade de ensino; ii) Abordar a EF como componente normativo curricular do eixo de linguagem contido no ciclo de formação humana na Educação Infantil, de acordo com as Políticas Educacionais de Cuiabá; iii) Ressaltar a dança aliada à EF como um conteúdo mediador do desenvolvimento das habilidades e/ou competências relevantes à Educação Infantil.

De natureza qualitativa, a abordagem metodológica envolveu a pesquisa bibliográfica e a análise documental, onde foram apreciados documentos oficiais do Município de Cuiabá, como Leis, Diretrizes e Políticas Educacionais; Projetos Políticos Pedagógicos de três Unidades Educacionais que atendem a Educação Infantil; a título de amostragem e planos de aula de professores que atuam com a disciplina de Educação Física nessa etapa inicial da Educação Básica. 
O aporte teórico que embasa a discussão tem como principais autores: Marques (1996); Scarpato (2001); Fachin (2006); Bregolato (2007); Cintra (2007); Andrade (2010); Pintado (2013); Machado e Silva (2019). Para além desses estudiosos/referência, foram feitas análise de pesquisas empíricas (Artigos, Dissertações e Teses) já publicadas em meios eletrônicos, como Revistas, Google Acadêmico; Scielo, entre outros, realizando um levantamento bibliográfico das últimas três décadas, cujos descritores principais foram: Educação Física; Educação Infantil; Dança; Desenvolvimento; Dança na Escola, tendo como critério de exclusão as publicações em outros idiomas e de inclusão as publicações exclusivamente em português, e que estivessem relacionadas à educação.

\section{Educação Física como componente normativo curricular contido no ciclo de formação humana: aspectos históricos}

No século $X I X$, a $E F$ esteve estreitamente vinculada às instituições militares e à classe médica. Esses vínculos foram determinantes, tanto no que diz respeito à concepção da disciplina e suas finalidades, quanto ao seu tempo de atuação e à forma de ser ensinada (BRASIL, 1997). Na tabela 01, apresentam-se alguns dos momentos históricos e/ou sociais que reforçam essa fase de afirmação da EF no contexto educacional brasileiro.

Tabela 01 - Alguns dos momentos históricos e sociais que envolvem a EF

\begin{tabular}{cl}
\hline Ano & \multicolumn{1}{c}{ Acontecimentos e/ou eventos que envolveram a EF } \\
\hline 1851 & $\begin{array}{l}\text { Reforma Couto Ferraz, o qual tornou obrigatória a Educação Física nas escolas } \\
\text { do município da corte; }\end{array}$ \\
1852 & $\begin{array}{l}\text { Decreto no } 8025 \text { de 16/03/1852, fomenta a prática da Educação Física para os alunos } \\
\text { das Escolas Normais; }\end{array}$ \\
1882 & $\begin{array}{l}\text { Rui Barbosa deu seu parecer sobre o Projeto 224, Reforma Leôncio de Carvalho, } \\
\text { referente ao Decreto } n^{\circ} 7247 \text { de } 19 / 04 / 1879 \text { da Instrução Pública, na qual defendeu } \\
\text { a inclusão da ginástica nas escolas e a equiparação dos professores de ginasticas } \\
\text { aos das outras disciplinas; }\end{array}$ \\
$\begin{array}{c}\text { A partir de } \\
1906\end{array}$ & $\begin{array}{l}\text { A Educação Física, ainda sob o nome de ginástica, foi incluída nos currículos } \\
\text { dos Estados: BA; CE; DF; MG, PE e SP; }\end{array}$ \\
1929 & $\begin{array}{l}\text { III Conferência Nacional de Educação, discutiu-se sobre os métodos, as práticas e } \\
\text { os problemas relativos ao ensino da Educação Física; }\end{array}$ \\
$\begin{array}{l}\text { Na elaboração da Constituição, faz-se a primeira referência explicita à Educação } \\
\text { Física em textos constitucionais federais, incluindo-a como prática educativa } \\
\text { obrigatória; }\end{array}$
\end{tabular}

1937 - 45 Com o Estado Novo, processo de industrialização e urbanização a Educação Física ganha novas atribuições;

1961 Lei oㅜ 4024 de 20/12/1961, 1a Lei de Diretrizes e Bases da Educação Nacional (LDB), ficou determinada a obrigatoriedade da Educação Física para o ensino primário e médio;

1968 Lei no 5540 de 28/11/1968, a Educação Física passa a ser considerada uma atividade prática voltada para o desempenho técnico e físico dos alunos;

1971 Decreto o 69450 de 01/11/1971 (2ª LDB), a Educação Física passa a ser considerada a atividade que por seus meios, processos e técnicas, tendo que desenvolver e aprimorar as forças físicas, morais, cívicas, psíquicas e sociais do educando;

Década O objetivo da Educação física passou a ser o desenvolvimento psicomotor do 1980 aluno, propondo retirar da escola a função de promover os esportes de alto rendimento;

Década Lei no 9394 de 20/12/1996 (LDBEN) buscou transformar o caráter que a Educação 1990 Física possuía, integrando-a à proposta pedagógica da escola;

Fonte: (Adaptado dos PCN's, 1997, v. $7 ;$ p. 19-22) 
Percebe-se, pelos dados, que os primeiros e/ou únicos objetivos da EF enquanto prática educativa obrigatória eram desenvolver aptidões físicas para os esportes de alto rendimento. A partir da década de 1970, começaram a surgir os direcionamentos para a aplicabilidade da disciplina no desenvolvimento psicomotor dos estudantes.

Entretanto, embora essas transformações anteriores tenham consolidado maior caráter pedagógico à disciplina, em muitos aspectos a prática pedagógica continuou priorizando as atividades físicas e de desporto nas aulas. Vale destacar, ainda, que somente no final da década de 1990, com a LDB (94/96), o cunho pedagógico da disciplina se fortaleceu como componente necessário ao desenvolvimento da aprendizagem.

À medida que a sociedade foi evoluindo, tanto estruturalmente como em conhecimento, a discussão sobre a relevância da EF nas instituições de ensino tornou-se mais evidenciada, principalmente nos debates sobre seu papel e dimensões políticas. Assim, essa história foi sendo construída gradativamente, na medida em que os objetivos educacionais nesse contexto também se tornaram mais amplos.

Os intensos debates que se seguiram ao longo da década dos anos 1990 que culminariam na aprovação da última LDB - Lei no 9394 de 1996, apontando rumos à uma nova tendência para ensino nacional e sobre a EF, sinalizavam uma nova ótica para o campo educacional, ao especificar em seu artigo 26 sobre a educação básica, que:

Art. 26: Os currículos do ensino fundamental e médio devem ter uma base nacional comum, a ser complementada, em cada sistema de ensino e estabelecimento escolar, por uma parte diversificada, exigida pelas características regionais e locais da sociedade, da cultura, da economia e da clientela (BRASIL, 1996).

Tal direcionamento, ao mesmo tempo em que abriu caminho para consolidação da disciplina, agregou ao debate um aspecto mais amplo sobre ação e reflexão do componente e sua inserção como parte integrante ao currículo, que o legislador pondera no parágrafo $3^{\circ}$ do referido artigo da seguinte maneira: "A Educação Física, integrada à proposta pedagógica da escola, é componente curricular obrigatória da educação básica, sendo sua prática facultativa ao aluno noturno" (BRASIL, 1996).

Dessa forma, a EF depois de décadas de intensa luta, deixa de ficar à margem dos outros componentes curriculares, agregando-se e ajustando-se a cada faixa etária orientada de acordo com as características do estudante dentro do contexto do projeto escolar.

Dentro desse ordenamento, o Estado de Mato Grosso inspirado no que dispõe a Constituição Estadual (MATO GROSSO, 2012), vinculado ao desejo social pelo fortalecimento a uma educação mais democrática e orientado por políticas e práticas educacionais busca responder a essa nova realidade priorizando a formação da pessoa humana.

Com as mudanças estruturais e as novas propostas de organização política, o Estado incorporou as premissas para um novo modelo de sociedade, e essas passaram a orientar a formulação das políticas e propostas segundo a concepção de educação capaz de romper as barreiras entre o pensar e o fazer, presentes nos projetos pedagógicos das escolas e nas organizações estruturais dos municípios (MATO GROSSO, 2012). 
Dessa forma, a Constituição Estadual de Mato Grosso em seu Capítulo II Seção I, Art. 237, determina que:

O Estado e Municípios organizarão seus sistemas de ensino de modo articulado e em colaboração, visando ao pleno desenvolvimento da pessoa humana, ao seu preparo para o exercício da cidadania com base nos seguintes princípios: I - a educação escolar pública, de qualidade, gratuita, em todos os níveis e graus, é direito de todos, conforme art. 10, inciso III, desta constituição; [...] (MATO GROSSO, 2004, p. 406).

No escopo desse dispositivo legal, em seu Art. 243 inciso V, que aborda a respeito às unidades escolares e sobre a disciplina de EF o legislador ressalta que:

As unidades escolares terão autonomia na definição de políticas pedagógicas, respeitando em seus currículos os conteúdos mínimos estabelecidos ao nível nacional, tendo como referência os valores culturais e artísticos nacionais e regionais, a iniciação técnico-científica e os valores ambientais: [...] V - a educação física é considerada disciplina regular e de matrícula obrigatória em todos os níveis de ensino (MATO GROSSO, 2004,p. 407-408).

Assim, sob esse viés, o Estado de Mato Grosso, por meio da Secretaria de Educação e órgãos como o Conselho Estadual de Educação (CEE/MT), a fim de atender a tais preceitos, estabelece diálogo com os 141 municípios do estado visando construir e articular o atendimento da disciplina de EF nas escolas públicas, bem como, de considerar o espaço de trabalho desse profissional habilitado para tal demanda, devido a sua relevância como componente do ciclo de formação humana em seus diversos níveis de ensino.

\subsection{Educação Física no contexto das escolas de Educação Infantil de Cuiabá: um processo inclusivo}

A dinâmica com que novos acontecimentos são inseridos no contexto social trazem consigo significativas alterações e essas por sua vez, influenciam expressivamente a sociedade no seu modo de se relacionar e na forma como os processos de construção do conhecimento passam a acontecer. Nesse meio, as instituições educacionais, consideradas os espaços mais adequados para sistematização desses saberes, buscam se adaptar a cada novo período e/ou momento, procurando responder às novas exigências sociais.

Nesse sentido a esfera municipal de Cuiabá, pela Lei n 673/63 cria no município pela primeira vez a estrutura da Secretaria Municipal de Educação e Saúde, buscando consolidar o princípio da participação democrática. No contexto do processo de redemocratização nacional, torna-se um marco ao nível local, exercendo e apresentando maior impacto após a promulgação da Constituinte de 1988 que culminaria com a efetivação da gestão democrática na educação. (MACHADO; SILVA, 2019).

E nesse universo a educação básica no município de Cuiabá foi se estruturando, tomando forma com a proposição de metas e objetivos consistentes de melhoria na qualidade da educação, como a Lei nํ 3201 de 10/11/1993, a chamada Lei da Gestão 
Democrática do Ensino da Rede Municipal de Cuiabá; o Convênio com a Universidade Federal de Mato Grosso (UFMT) no ano de 1994 para elaborar o projeto de reorganização curricular das escolas da rede municipal de Cuiabá, que encontra suporte advindo da LDB (1996), e em 2009 com a Lei o 5289/09 ao criar o Sistema Municipal de Educação ao nível regional, inova na forma de organização e gestão da escola.

Atualmente, a Política Educacional da Rede de Municipal de Ensino de Cuiabá é conhecida pela terminologia Escola Cuiabana, estando materializada na obra: "Escola Cuiabana, cultura, tempos de vida, direitos de aprendizagem e inclusão", e nos Documentos de Referência Curricular da Rede Municipal de Ensino (DRC/SME/Cuiabá, 2020) - para Educação Infantil, Ensino Fundamental e Educação de Jovens e Adultos estes apresentando as respectivas Matrizes Curriculares (CUIABÁ, 2021).

Balizada no contexto de diversas leis e/ou normativas direcionadoras no âmbito educacional, a proposta de ensino da rede municipal de Educação de Cuiabá foi sendo configurada, como ressaltam Machado e Silva (2019, p. 77), tendo como ponto de partida da Escola Cuiabana, os saberes construídos e revisados no sentido de

[...] elaborar uma proposta educacional que considere a formação e o desenvolvimento humano pleno, enraizada na realidade local, que envolva a diversidade étnica, com a presença dos povos originários, colonizadores, migrantes e imigrantes, os biomas da região, como o Cerrado, Pantanal e Amazônia, e outros elementos históricos, culturais e ambientais. Esta proposta, embora valorize a realidade local, não exclui o conhecimento de outras realidades e culturas.

Nesse cenário, a Educação Infantil assume um local de destaque, por se tratar de um espaço onde podem e devem ser iniciadas experiências significativas para 0 desenvolvimento de forma gradual e sequenciada. A escolarização nessa fase indica de uma forma mais específica a materialização da realidade para essa criança e de sua cidadania como sujeito de direito, tendo tais reconhecimentos abordados, destacados e inseridos dentro do ordenamento jurídico nacional (CF, 1988; ECA, 1990; LDB,1996; RCNEI, 1998), e mais recentemente a BNCC (2017) com o avanço de seus objetivos socioemocionais.

Todo esse movimento de intenso processo de revisão das ações e práticas educativas voltado ao desenvolvimento da Educação Infantil, encaminhou a busca de situações mediadoras de aprendizagem centradas na Educação Básica. Sendo essa a primeira etapa dessa nova realidade a ser vivida pelas crianças, o seu desenvolvimento integral, em seus aspectos físico, psicológico, intelectual e social, apresenta-se como objetivo fundamental.

Nessa caminhada, as políticas educacionais do município de Cuiabá vêm sendo reestruturadas ao longo das últimas duas décadas, e alguns desses aspectos estruturais são reforçados por meio do crescimento da rede e como esses estão sendo absorvidos. Quando se observa o último Censo publicado, Censo Escolar 2018, que aponta números significativos de matrículas (Tabela 02) e de número de estabelecimentos escolares (Tabela 03) que compõem a rede municipal de ensino, podese ter uma visão geral da dinâmica vivenciada pela rede. 
Tabela 02 - Matrículas na rede municipal de ensino de Cuiabá-MT: ano base censo escolar 2018

\begin{tabular}{|c|c|c|c|c|c|}
\hline \multirow{2}{*}{$\begin{array}{l}\text { ANO } \\
2018\end{array}$} & \multicolumn{2}{|c|}{ Educação Infantil } & \multicolumn{2}{|c|}{$\begin{array}{c}\text { Ensino fundamental } \\
\text { regular }\end{array}$} & \multirow{2}{*}{$\begin{array}{c}\text { Educação } \\
\text { Jovens e } \\
\text { Adultos }\end{array}$} \\
\hline & Creche & Pré-escola & Anos Iniciais & $\begin{array}{l}\text { Anos } \\
\text { Finais }\end{array}$ & \\
\hline Total & 8342 & 11486 & 24292 & 4985 & 1154 \\
\hline
\end{tabular}

Fonte: (Adaptado de "Escola Cuiabana", 2019, p.25)

Vale destacar que dos mais de 50 mil alunos matriculados na rede municipal em Cuiabá/MT, aproximadamente 39\% (19.828 alunos) estão matriculados na Educação Infantil (creches e pré-escolas) e algo mais de 59\% (29.823 alunos) são do Ensino Fundamental regular, divididos entre os anos iniciais e finais, todas essas crianças distribuídas nas 162 unidades de ensino da rede.

Tabela 03 - Quantitativo de unidades educacionais da rede municipal de Cuiabá censo 2018

\begin{tabular}{cc}
\hline Unidades Educacionais & Quantidade de Unidades \\
\hline - Centros Emergenciais de Educação Infantil (CEEI) & 02 \\
- Centro Municipal de Educação Infantil (CMEI) & 20 \\
CRECHES & 51 \\
- Escola Municipal de Educação Básica (EMEB) & 81 \\
- Escola Municipal de Educação Básica do & 08 \\
Campo (EMEBC) & 162 \\
\hline TOTAL &
\end{tabular}

Fonte: (Adaptado de "Escola Cuiabana", 2019, p. 26).

Num processo de ordenamento das etapas da Educação Básica, algumas instituições (EMEBs) mantidas pela Prefeitura de Cuiabá passaram a atender apenas estudantes da Fase Final do Ensino Fundamental. Outras, diante da estrutura, recebem crianças da Educação Infantil (04 e 05 anos) até o final da $2^{\underline{a}}$ Fase (5o ano). Nessa disposição, os Centros Municipais de Educação Infantil (CMEI), foram organizados para receber crianças do maternal (0) até os cinco (05) anos.

Diante da demanda em algumas regiões de Cuiabá devido a esse processo, foram criados os Centros Emergenciais de Educação Infantil (CEEI), que recebem crianças de dois (02) anos até a etapa da Educação Infantil (04 e 05 anos). Essas unidades educacionais foram implantadas a título de emergência apenas em alguns bairros do município, onde foram observadas as necessidades populacionais e a demanda de vagas ofertadas pelas instituições já em funcionamento.

Assim, na busca em promover e/ou articular o avanço do processo de ensino e aprendizagem, a rede municipal de educação de Cuiabá, balizada pelas suas normativas e/ou dispositivos legais que apontam caminhos a serem norteados, segue o disposto no art. $3^{\circ}$ das Diretrizes Curriculares Nacionais para Educação Infantil (DCNEI,2010), que pontua o direcionamento de como deve ser concebido o currículo nessa fase/etapa da educação: 
[...] como um conjunto de práticas que buscam articular as experiências e os saberes das crianças com os conhecimentos que fazem parte do patrimônio cultural, artístico, ambiental, científico e tecnológico, de modo a promover o desenvolvimento integral de crianças [...] (BRASIL, 2010, p. 86).

As características curriculares apontadas ressaltam uma abordagem também voltada para formação da criança nos espaços educativos, que para se chegar à formação ampla do sujeito posterior e gradativamente, será preciso a estimulação do mundo interno e externo, de modo que, se favoreça o desenvolvimento integral da criança.

Nessa abordagem, Roger e Bertan (2002, p. 31), concordam que para "o indivíduo alcançar seu equilíbrio e maturidade, ou seja, tornar-se pessoa faz-se necessário procurar sua unidade interior e exterior". Cintra (2007; p. 20-21) contribui destacando que, para que ocorra tal situação "o processo educacional da aprendizagem deverá ser balizado nouso da liberdade humana, uma vez que, ao se conhecer e apropriar-se de si mesmo, a pessoa evolui e floresce".

Marcos regulatórios, como a LDB (1996), apontam como sendo um dos objetivos da Educação Infantil, o desenvolvimento global da criança até os 05 anos de idade sendo esta, a etapa inicial da Educação Básica. Nesse contexto, a instituição - escola é o espaço que deverá proporcionar aos educandos diversas situações desafiadoras, que os conduzirão ao encontro da capacidade de aprender a aprender, principalmente perante as suas indagações, tornando-se pessoas detentoras de uma visão ampliada do mundo, onde se valorizam suas experiências estimulando novas descobertas na formação (BRASIL, 1997).

Dessa forma, a primeira década dos anos 2000, foi marcada por mudanças significativas das políticas educacionais na Rede Municipal de Ensino de Cuiabá, ao passar a considerar o tempo e o espaço para aprender, e nesse sentido deve-se destacar a relevância para a Escola Cuiabana do Projeto Saranzal e os avanços trazidos pela EscolaSarã, bem como a reorganização curricular ocorrida no período e demais propostas utilizadas pela Secretaria Municipal de Educação (SME) (MACHADO; SILVA, 2019).

O projeto Saranzal foi elaborado na década de 1990 durante a transição da escola Seriada para a Escola Ciclada, cuja principal característica era "dar uma nova organização aos tempos e espaços para aprender", pois a garantia da aprendizagem "[...] passa a ser uma meta fundamental quando pensamos em uma sociedade sem exclusão, voltada aos interesses da maioria" (ESCOLA CUIABANA, 2019, p. 23). Posteriormente, esse projeto foi debatido com a Rede, fundamentado e transformado na política educacional denominada Escola Sarã: Cuiabá nos Ciclos de Formação, publicado em 2000. Cuiabana,

De acordo com o exposto na última organização da Política Educacional, Escola

[...] a proposta da Escola Sarã inovou os processos de elaboração curricular e apontou para uma nova forma de organização da escola e sua gestão, considerando os tempos e espaços para aprender, trazendo como princípios democráticos a garantia de um ensino de qualidade e uma aprendizagem significativa para todos. ${ }^{4}$

${ }^{4}$ CUIABÁ, 2019. Loc. Cit. 
Ainda, segundo Machado e Silva (2019), a partir de 2010, balizado pelas experiências dos anos anteriores, e dentro desse universo pela consolidação por uma matriz curricular que atendesse a crescente demanda estudantil que a Secretaria Municipal de Educação vinha assumindo, o órgão buscou adequar-se e assim partir para a construção de uma identidade local, sustentada pelas experiências vivenciadas nas unidades escolares, nas orientações das Diretrizes Curriculares Nacionais, bem como em uma proposta pedagógica para Educação Infantil em Cuiabá situada nas matrizes interacionistas e sociointeracionistas.

Tais pressupostos corroboram para evidenciar dentro da área de linguagem a EF como um componente essencial para a formação da criança na Educação Básica desta rede municipal de ensino em seus diversos aspectos, ressaltando-a como uma disciplina com competências e saberes fundamentais para a formação e construção do sujeito.

Assim, nesse enfoque da reorganização curricular, no ano de 2014, é aprovada pelo poder legislativo municipal de Cuiabá a Lei oㅡ 5871 de 30/09/2014, no artigo 1ํ:

Fica obrigatória para docência da disciplina de Educação Física na Educação Infantil e Fundamental a formação em curso de licenciatura em Educação Física; - Parágrafo Único: a obrigatoriedade que trata o caput deste artigo aplica-se as instituições de ensino públicas e às instituições de ensino privadas (CUIABÁ, 2014).

Batista (2015, p. 37) ressalta também que "é importante lembrarmos que a EF Escolar é uma área que em seus conteúdos, abrange diversos conhecimentos tendo como objeto de estudo o movimento humano realizado de maneira integral e única em cada indivíduo".

Nesse contexto, entende-se que a EF, ao explorar os movimentos, gestos, sons, formas, relacionamentos, na escola e fora dela, contribuirá com o desenvolvimento do currículo de forma orgânica, corroborando na superação e organização dos aspectos das áreas de conhecimento, via interação e articulação curricular em seus diferentes saberes. Machado e Silva (2019, p. 110) complementam que

É extremamente importante para a criança poder explorar o ambiente, vivenciando os momentos que proporcionem a ela 0 pleno desenvolvimento de suas capacidades, tanto físicas, quanto motoras, inserindo os conhecimentos e saberes em seu processo de humanização. (MACHADO; SILVA, 2019, p. 110).

Isso significa que a EF articulada com as experiências de vida das crianças, pode transpor o ambiente educativo escolar para além da estética e do rigor das atividades desenvolvidas sob uma organização curricular estanque e desarticulada com a realidade dos diversos ambientes educativos que influenciam o desenvolvimento infantil.

Dessa forma, a rede municipal de ensino de Cuiabá, por meio da SME, em consonância com os dispositivos legais, e de acordo com as orientações da BNCC, tem buscado articular e/ou consolidar um currículo que mobilize os campos de experiências para que as crianças tenham vivências e aprendizagens significativas no seu processo de humanização e desenvolvimento. 


\subsection{A dança na Educação Física escolar como conteúdo mediador do desenvolvimento das habilidades necessárias na Educação Infantil}

Segundo Gouveia-Pereira (2008) a escola permite o confronto diário com normas e regras de comportamento institucional, que vão para além das relações pessoais e informais. Assim, na intensidade desses confrontos, das mudanças de concepções, ações e atitudes tendem a influenciar diretamente os espaços educacionais, e esses por sua vez, têm vivenciado constantes revisões em seus pilares organizacionais e formativos, seja por meio de ações individuais ou coletivas. Muitos desses processos históricos de debates e discussões, têm moldado a educação brasileira nas últimas décadas, principalmente quanto aos aspectos relacionados ao processo de desenvolvimento e aprendizagem das crianças nos espaços coletivos. Nesse direcionamento, Andrade (2010, p. 24) afirma que:

Atualmente, o reconhecimento da criança enquanto sujeito social e histórico, detentora de direitos sociais, faz da educação infantil uma exigência social, ocupando no cenário da educação brasileira um espaço significativo e relevante. Paralelamente ao quadro de transformações societárias aliadas aos movimentos sociais e estudos acerca da infância, tem sido intensificado o reconhecimento da importância da educação das crianças para o pleno desenvolvimento das potencialidades do ser humano.

Portanto, aquilo que somos e o que representamos relacionados aos componentes do desenvolvimento do ser, Pintado (2013) diz que a representação disso, está nos pensamentos, sentimentos e experiências que ao longo da vida é perceptível, sobretudo na primeira fase de existência. Nessa perspectiva, Serrano (2013), afirma que a configuração daquilo de como o sujeito se vê, ocorre por meio de áreas distintas, sendo elas: a área corporal com ênfase nas habilidades e aparências físicas, a acadêmica, a social e familiar.

Com relação aos aspectos corporais, os PCN's (1997) e mais recentemente a BNCC (2017) apontam em suas diretrizes que a estimulação do crescimento e desenvolvimento da aprendizagem pode e deve ter suporte na possibilidade do uso dos movimentos corporais, de modo que, a criança se aproprie do processo de construção de conhecimento pertinente ao seu corpo e ao movimento trabalhado e organize progressivamente sua autonomia a partir dessas experiências (CINTRA, 2007).

Alguns conceitos sobre a utilização da dança na educação são discutidos por autores como Delors (1996), Scarpato (2001), Cintra (2007), segundo os quais a dança surge como uma abordagem diferenciada que pode contribuir na formação da criança na fase da Educação Infantil, bem como, em toda sua trajetória acadêmica em nível Fundamental e Médio. Scarpato (2001, p. 84) expõe que "é necessário a desmistificação da dança-educação, ao destacar sua relevância e contribuições à formação crítica e ao desenvolvimento do indivíduo como ser humano, estabelecendo a integração de diversas habilidades e competências ao aluno". Dessa forma, a dança enquanto uma atividade que privilegia a educação motora consciente e global é uma ação pedagógica, bem como psicológica (CINTRA, 2007). Nesse direcionamento as novas propostas curriculares da Educação Infantil "estão inserindo a dança nos planejamentos das aulas, e por meio desta as crianças aprendem a se expressar corporalmente, permitindo-lhes atuar de forma autônoma no meio em que vivem" (SANTOS et al. 2015, p.6). 
Para Cintra (2007, p. 36) a escola "é o espaço central dessa construção de valores, consolidação de práticas pedagógicas que conduzem a liberdade, a convivência social, solidariedade humana, inclusão social e cidadania". Algumas dessas situações estão sendo vivenciadas em diversas instituições de ensino em âmbito nacional e/ou em outros países, nas quais a dança apresenta-se como suporte da aprendizagem, fato que ocorre, por exemplo, no contexto educacional de estabelecimentos como o Colégio Nova Era ${ }^{5}$ e Summerhill School6, em que o objetivo da abordagem, sobretudo, entre outros, é oferecer por meio da dança educativa, o equilíbrio emocional como principal via para a aprendizagem e felicidade. A esse respeito, Scarpato (2001, p. 9), enfatiza que:

O aprendizado da dança educativa integra o conhecimento intelectual e a habilidade corporal e criativa do aluno. Daí, a alfabetização é um processo pelo qual a criança codifica e decodifica o mundo que a cerca, processo que não atinge somente o espaço cognitivo do aluno, mas o aluno como um todo: emocional, social, corporal etc.

Para Delors (1996) ao se trabalhar com a Educação Infantil dentro das concepções metodológicas da dança-educação, compreendida na ação-sensação-reflexão, fará com que o aluno se envolva naquilo que são os pilares que constitui a educação: aprender a ser, aprender a fazer, aprender a conhecer e aprender a viver juntos.

Embora os conceitos de dança-educação ou dança-educativa aqui expostos por vários autores possa representar, grosso modo, a inclusão da dança como uma disciplina nos currículos escolares, é fato que na maioria das instituições públicas de ensino regular não há essa referência nas matrizes curriculares e diretrizes educacionais. Entretanto, desenvolvendo um olhar mais pragmático sobre as concepções metodológicas que podem designar esses termos (dança-educação; dança-educativa; dança-movimento), o fato é que, ao considerarmos o movimento como um elemento indissociável da dança, garantimos o acesso aos benefícios que esta pode fornecer ao desenvolvimento infantil.

Nesse sentido, depreende-se dessa ideia, que a utilização da dança como suporte pedagógico para o desenvolvimento infantil, não necessariamente exige o rigor do ensino da dança como uma nova disciplina ou componente curricular, mas sim lançar mão dos seus recursos como aliada ao processo de formação integral da criança, por meio do caráter lúdico, comunicativo e expressivo que esta empresta ao uso dos movimentos como possibilidades de interação corpo/mente. Assim, conforme ressaltam Apolinário e Grando (2021):

A dança na escola não deve priorizar a realização perfeita dos movimentos, ou seja, realizá-los em um padrão imposto que pode gerar competitividade entre os alunos, pois se deve entender que o movimento é uma forma de expressão e comunicação (APOLINARIO; GRANDO 2021, p. 2).

\footnotetext{
${ }^{5}$ Colégio situado na região sul do Estado de São Paulo, foi a primeira escola do Brasil a acreditar nessa proposta valorizando a dança educativa inspirada nos princípios freinetianos (SCARPATO, 2001, p.8).

6 Nova escola (2011). Trata-se de um grupo de instituições que conjugam algum tipo de gestão democrática com flexibilização curricular, em que as aulas são opcionais. A reportagem é de uma brasileira que em 2011 , à época da reportagem, fazia dois anos que trabalhava como house parent (mãe de casa) já que em Summerhill as crianças são internas durante 0 período das aulas. Disponível em <https://novaescola.org.br/conteudo/1508/conheca-summerhill-a-escola-em-que-o-aluno- pode-quase-tudo >
} 
Portanto, a dança como ferramenta lúdica, é uma via que pode sistematicamente corroborar para a criança na sua alfabetização, sendo que através do seu corpo surge o elo, onde esta cria e ressignifica os conceitos ao seu redor, ampliando seus referenciais, ajudando-a a construir sua própria visão de mundo, e ampliando assim sua aprendizagem de maneira mais significativa.

\subsection{Dança e Educação Infantil - um olhar sobre as possibilidades ao desenvolvimento das crianças}

$\mathrm{Na}$ Política Educacional de Cuiabá, o conceito de dança está relacionado às expressões culturais e ao movimento corporal, como um conteúdo ou estratégia nas aulas de Educação Física, coadunando com as orientações dos PCNs da área e mais recentemente, da BNCC. Nessa perspectiva, o que se pretende ao discutirmos o campo híbrido entre dança e educação é, como proposto em um dos objetivos do estudo, ressaltar a dança aliada à EF como um conteúdo mediador do desenvolvimento das habilidades e/ou competências relevantes à Educação Infantil.

Neste sentido o RCNEI (1998) em suas linhas introdutórias deixa evidente que a maneira como a criança anda, corre, arremessa, salta, é o somatório de suas relações sociais consigo mesma e com o meio que a cerca. Todas essas mudanças são motivadas por diferentes necessidades e possibilidades corporais humanas. Tais ações somamse ao comportamento dos seres humanos, constituindo-se assim numa cultura corporal. O citado referencial aponta ainda que a dança, os jogos, as brincadeiras, as práticas esportivas vão se tornando mais evidenciadas à medida que o uso de diferentes gestos, posturas e expressões corporais passam a ser reproduzidas com mais intencionalidade.

Portanto, tais atitudes e/ou comportamentos indicam que a criança não deverá ser mero espectador no elo que resulta a sua aprendizagem, mas sim, participante ativo dentro da engrenagem da construção de seu conhecimento e/ou habilidades. Nesse direcionamento as Diretrizes Curriculares Nacionais para Educação Infantil (DCNEI, 2010) em seu art. 4ํㅜ refere-se às crianças como sendo:

Sujeito histórico e de direitos que, nas interações, relações e práticas cotidianas que vivencia, constrói sua identidade pessoal e coletiva, brinca, imagina, fantasia, deseja, aprende, observa, experimenta, narra, questiona e constrói sentidos sobre a natureza e a sociedade produzindo cultura (DCNEI, 2010, p. 86).

O trecho supracitado, apenas reforça o entendimento da criança como ser social e ativo no processo da aprendizagem e do seu desenvolvimento como um todo, e como potencial criador e reprodutor intencional de seus movimentos, assim criando sua cultura corporal e sua autonomia no meio em que se encontra. Bregolato (2007) defende que os movimentos espontâneos, baseados pelo motivo sentimental são de fato ocasionados pela presença da musicalidade, elevando suas habilidades rítmicas com a comunicação sobre a sua linguagem do corpo e suas respostas psíquicas e motoras. Tais fatos determinam sua permanência com o processo de socialização.

Dessa maneira identifica-se por meio do movimento um suporte ao desenvolvimento da criança na fase da Educação Infantil no espaço escolar. Como destaca o RCNEI (1998, p. 16): 
O Trabalho com movimento contempla a multiplicidade de funções e manifestações do ato motor, propiciando um amplo desenvolvimento de aspectos específicos da motricidade das crianças, abrangendo uma reflexão acerca das posturas corporais implicadas nas atividades cotidianas, bem como atividades voltadas para a ampliação da cultura corporal de cada criança.

Contudo, compreendemos que a aprendizagem não se alcança com uma aplicação tecnicista pré-estabelecida, mas sim com oportunidades de descobertas coletivas e compartilhadas, buscando assim significações acerca da sua contribuição com 0 conhecimento e experimentos de ação (SACRISTÁN; PÉREZ GÓMES, 2002).

Nesse sentido, a dança no âmbito escolar se torna ferramenta muito importante principalmente para explorar o próprio corpo de uma forma diferenciada, ou seja, promove capacidades de o aluno romper paradigmas em movimentos dos mais variados níveis a fim de se conhecer dançando.

A dança, segundo Nanni (1995) é vista desde os tempos remotos como expressão da arte, destacando não somente emoções, mas também as características e peculiaridades de um povo, estando sempre presente, desde eras pré-históricas até nossos dias, com suas atribuições inerentes à cultura humana. Entretanto, em cada fase da sociedade, ela adquiriu novos significados e objetivos, bem como, na sua cultura.

Para Vygotski (1984), a cultura fornece aos sujeitos os sistemas simbólicos de representações e suas significações, que se convertem em organizadores do pensamento, instrumentos aptos para representar a realidade. Scarpato (2001) contribui destacando o uso da dança na sala de aula, ao se trabalhar com o corpo cria-se a consciência corporal e a criança começa observar e indagar com mais sensibilidade às situações à sua volta.

A esse respeito Barilli e Cintra (2013) acrescentam que por meio da dança proporciona-se um momento em que podemos tocar nosso interior, por meio dos sentidos, da leitura de mundo com uma nova linguagem, e assim a educação cumpre sua função. As autoras complementam ressaltando que nossas experiências estão registradas em nosso corpo e interagem com outros corpos; não possuímos corpos, mas somos o próprio corpo, portanto, instrumento no processo de ensinar e aprender. Barreto $(2008$, p. 66$)$ complementa que a dança pode propiciar:

Autoconhecimento, estimular vivência da corporeidade na escola, proporcionar aos educandos novos relacionamentos estéticos com outras pessoas e com o mundo, incentivar a expressividade dos indivíduos, possibilitar a comunicação não verbal e os diálogos corporais na escola". Sendo assim ela permite a sensibilização das pessoas promovendo relações mais equilibradas e harmoniosas através de sua apreciação.

De acordo com o estudo de Silva et. al. (2020), embasado em neurociências, a vivência da dança libera hormônio do prazer, endorfinas, serotonina, ocitocina e dopamina e configura-se como atividade privilegiada para conectar corpo e mente. E ainda sobre isso, concluem, defendendo a ideia de que a dança de forma prazerosa, irá despertar habilidades nos alunos, aumentando o seu repertório cognomotor. 
Assim, ao associar-se a dança à dinâmica das ações, direcionadas na busca por elementos como expressividade e o equilíbrio, tende-se a moldar as potencialidades corporais e nessa intencionalidade a construção da aprendizagem vai se criando. Bregolato (2007) entende que por meio da livre expressão, a criança se motiva a encontrar em si própria a inspiração em relação a sua movimentação, sabendo que isso proporciona liberdade de sentimentos e seus pensamentos fluem no movimento dançado.

Portanto, observa-se que nos espaços coletivos não domésticos, quer sejam creches e/ou instituições afins, responsáveis por esse primeiro contato de educação e cuidado, faz-se necessário que tais ambientes tenham em suas diretrizes propostas de orientações pedagógicas bem definidas. Desse modo, há que se priorizar práticas mediadoras que contemplem a dança como uma ferramenta de múltiplas possibilidades ao fortalecimento do processo da aprendizagem, renovação e apropriação do conhecimento, de modo que esse estudante tenha oportunidades de alcançar seu pleno desenvolvimento, de maneira mais equilibrada e significativa, corroborando com a sua educação e contribuindo para formação deste como um ser social pleno e crítico.

\section{Trajetória metodológica da pesquisa}

Considerando os meios existentes e, do ponto de vista dos objetivos da pesquisa, esse estudo é de natureza qualitativa, tendo em vista sua relação com os fenômenos educativos, que, segundo Minayo (2014) envolvem a subjetividade das relações escolares que não se explicam pela quantificação.

No universo dos vários aspectos que permeiam essas relações, a utilização da dança como estratégia metodológica nas aulas de Educação Física com crianças da Educação Infantil tornou-se objeto desse estudo diante da constatação do limitado repertório de atividades corporais envolvendo movimento utilizadas tradicionalmente pela EF, priorizando mais especificamente as práticas corporais esportivas no auxílio ao desenvolvimento motor dos alunos. Dessa forma, entende-se que trabalhar a cultura corporal do movimento por meio de outras práticas, como a dança enquanto componente que integra corpo e mente, proporcionaria aos estudantes melhor desempenho cognitivo e motor.

Dentre a gama de possibilidades de uma investigação dessa natureza, optou-se pela pesquisa de caráter exploratório e descritivo, lançando mão dos recursos das pesquisas bibliográficas e análise de documentos, como os planos de aula, Projetos Políticos Pedagógicos de algumas instituições que atendem a Educação Infantil no Município de Cuiabá, Mato Grosso, bem como as diretrizes da Política Municipal para a Educação (Escola Cuiabana, 2019); as resoluções e diretrizes Nacionais como RCNEI (1998), DCNEI (2010) e a Base Nacional Comum Curricular (BNCC, 2017).

Para Trigueiro (2014), a pesquisa bibliográfica visa ao conhecimento e análise das principais teorias relacionadas a um tema e é parte indispensável de qualquer tipo de pesquisa, podendo ser realizada com diferentes finalidades, sendo esta em si um tipo de pesquisa. Assim, para constituição dos trabalhos preliminares, utilizou-se como recursos a pesquisa exploratória e descritiva sobre o tema. Na etapa da pesquisa exploratória buscouse coletar maiores informações sobre o assunto e assim facilitar a delimitação do trabalho. Como destaca Andrade (1999), é o momento de se avaliar a possibilidade de desenvolver uma boa pesquisa definindo os objetivos ou formulando as hipóteses ou descobrindo novos enfoques para o trabalho. 
Nesse sentido, fez-se análise de materiais já produzidos e publicados na literatura, bem como resultados de pesquisas empíricas (Artigos, Dissertações e Teses), além de visitas e pesquisas a banco de dados (Revistas; Google Acadêmico; Scielo; etc), realizando um levantamento bibliográfico das últimas três décadas, cujos descritores principais foram: Educação Física; Educação Infantil; Dança; Desenvolvimento; Dança na Escola, tendo como critério de exclusão as publicações em outros idiomas, as que tratam de situações não relacionadas ou que apresentam pouca qualidade metodológica. Nos critérios de inclusão foram selecionadas as publicações com idiomas em português e que estivessem relacionados à educação e ao tema em questão. Todo assunto foi ordenado em fichas as quais continham cabeçalho, referência bibliográfica e corpo do estudo.

A pesquisa documental como técnica de recolha de dados, conforme relatado por Flick (2009), permite a contextualização das informações produzidas pela coleta empírica, resultando em uma análise comparativa que pode auxiliar no cruzamento dos dados coletados e confirmar (ou não) declarações e sentidos implícitos nos discursos resultantes da proposta do documento.

Os documentos produzidos nas instituições e/ou órgãos responsáveis pela educação, como o PPP e Diretrizes Educacionais, nesse sentido, vêm corroborar essa contextualização, pois sua elaboração já possui a finalidade a intencionalidade explícita de nortear o trabalho pedagógico no contexto educativo. Conforme pondera Andrade (1999, p. 124)

Nesse tipo de pesquisa, os fatos são observados, registrados, analisados, classificados e interpretados, sem que o pesquisador interfira neles. Isto significa que os fenômenos do mundo físico e humano são estudados, mas não manipulados pelo pesquisador.

Nessa direção, passou-se à análise dos dados coletados pelo processo de descrição e interpretação que, nesse sentido, permitiram a reflexão a partir da análise documental e das considerações teóricas disponibilizadas pelo conhecimento científico já produzido sobre o tema.

\section{Educação Física e a dança: Políticas Educacionais e Projetos Políticos Pedagógicos}

O texto base Escola Cuiabana - Política Educacional da Secretaria de Educação de Cuiabá - (2019) faz referência à segunda infância, idade entre 03 e 06 anos, como o período em que se intensifica o desenvolvimento das habilidades motoras, como subir escadas, correr, saltar, andar com equilíbrio, usar objetos e fazer movimentos com coordenação.

O ingresso na escola auxilia o desenvolvimento dessas habilidades, uma vez que faz parte das atividades pedagógicas o exercício das funções físicas e motoras da criança. Desenvolve o processo de aquisição das aprendizagens formais do ler e escrever, a construção do pensamento lógico matemático (CUIABÁ, 2019, p. 57).

Em relação à dança, o documento enfatiza atividades de expressão cultural, utilizando-se das práticas e expressões culturais do próprio aluno, "[...] tendo como base a apropriação da cultura do grupo familiar, da cultura local, da cultura regional, da cultura 
nacional e da cultura internacional" (2019, p. 73). Nesse contexto, traz o movimento e a expressão corporal como base para "[...] fazer com que a pessoa descubra formas de mover-se e expressar-se. Mais do que precisão, é necessário expressão e sentimento em cada pequeno movimento corporal"7.

A organização curricular pedagógica para a Educação Infantil da Escola Cuiabana está pautada na proposta da BNCC, recomendando a organização do trabalho a partir dos Campos de Experiência para todas as áreas do conhecimento. Da mesma maneira, ao serem analisados alguns Projetos Políticos Pedagógicos de Unidades Escolares que atendem crianças da Educação Infantil na Rede Municipal de Cuiabá, percebe-se que, de forma análoga, esses documentos não apresentam especificidades em relação aos tipos de abordagem metodológica ou aos conteúdos desenvolvidos nessa etapa inicial da escolarização básica.

O PPP da EMEB Maria Tomich Monteiro da Silva, apresenta, no ano 2021, ementa para a Educação Infantil conforme os Eixos Estruturantes e Campos de Experiências propostos na BNCC e no e-book Escola Cuiabana, com os objetivos que, subentende-se, devem orientar de forma generalizada a ação pedagógica. A expressão corporal e o movimento estão implícitos no uso das diversas manifestações de linguagem.

\begin{abstract}
Utilizar as diferentes linguagens (corporal, musical, plástica, oral e escrita) ajustadas às diferentes intenções e situações de comunicação, de forma a compreender e ser compreendido, expressar suas ideias, sentimentos, necessidades e desejos e avançar no seu processo de construção de significados, enriquecendo cada vez mais sua capacidade expressiva (PPP, 2021, p. 46).
\end{abstract}

$\mathrm{Na}$ organização e estrutura curricular para essa etapa da escolarização, o documento expressa a intencionalidade de "[...] desenvolver um currículo como um conjunto de práticas que buscam articular as experiências e os saberes das crianças com os conhecimentos que fazem parte do patrimônio cultural, artístico, científico e tecnológico" (PPP, 2021, p. 54).

Nesse mesmo contexto, os documentos que regem as demais instituições que atendem a Educação Infantil (CMEls, Creches e CEEls) são elaborados conforme orientações da SME e propostas da BNCC, considerando as especificidades de cada órgão. Sob essa ótica, ao serem analisados esses documentos, pode-se inferir que as políticas educacionais do município não trazem referências específicas sobre metodologias e práticas nesse contexto, cabendo ao professor estabelecer suas ações nesse sentido.

\title{
4.1 Educação Física e a dança: propostas nos planejamentos de ensino
}

Embora a Dança como conteúdo ou estratégia metodológica nas aulas de Educação Física não seja referência específica nos Projetos Políticos Pedagógicos das escolas ou nos documentos oficiais das Políticas Educacionais do Município, está contemplada em alguns dos Planos de Ensino dos educadores diante dos eixos norteadores, direitos e objetivos de aprendizagem, conforme sugere a BNCC no Campo de Experiência corpo, gestos e movimentos (Quadro 01).

7 CUIABÁ (2019, Loc. Cit.) 
Quadro 01 - Objetivos do currículo e de aprendizagem Novembro/Dezembro

\begin{tabular}{|c|c|c|c|c|}
\hline EIXOS NOR & $\begin{array}{r}\text { PLANEJK } \\
\text { EADORES: INTER }\end{array}$ & $\frac{\text { IENTO/ PERIC }}{\text { O̧ÕES E BRIN }}$ & $\begin{array}{l}\text { O: 03/11 A 14/12/202 } \\
\text { ADEIRAS }\end{array}$ & \\
\hline & endizagem: Con & & rticipar / Explorar / E & \\
\hline & & CAMPOS DE E & KERIÊNCIA & \\
\hline $\begin{array}{l}\text { O Eu, o } \\
\text { Outro e o } \\
\text { Nós }\end{array}$ & $\begin{array}{l}\text { Corpo, Gestos e } \\
\text { Movimentos }\end{array}$ & $\begin{array}{l}\text { Escuta, Fala, } \\
\text { Pensamento } \\
\text { e Imaginação }\end{array}$ & $\begin{array}{c}\text { Traços, Sons, Cores } \\
\text { e Imagens }\end{array}$ & $\begin{array}{l}\text { Espaço, Tempo, } \\
\text { Quantidades, } \\
\text { Relações e } \\
\text { Transformações }\end{array}$ \\
\hline $\begin{array}{l}\text { Conhecime } \\
\text { dramática; }\end{array}$ & $\begin{array}{l}\text { e saberes: } \\
\text { sidade de man }\end{array}$ & $\begin{array}{l}\text { rio; Movim } \\
\text { ões artístic }\end{array}$ & $\begin{array}{l}\text { os corporais; Lingu } \\
\text { e culturais. }\end{array}$ & corporal, musical \\
\hline $\begin{array}{l}\text { Objetivo } \\
\text { híbrido, as }\end{array}$ & $\begin{array}{l}\text { rrículo: Promo } \\
\text { ando o direito à }\end{array}$ & $\begin{array}{l}\text { e realizar Ir } \\
\text { endizagem }\end{array}$ & $\begin{array}{l}\text { ões e Brincadeiras } \\
\text { rianças da segunda }\end{array}$ & $\begin{array}{l}\text { s crianças no ensino } \\
\text { cia Pré-escola. }\end{array}$ \\
\hline $\begin{array}{l}\text { BJETIVOS } \\
\text { EI03CG01 - } \\
\text { emoções, ta } \\
\text { EI03CG02 - } \\
\text { e reconto de } \\
\text { EI03CG03 - }\end{array}$ & $\begin{array}{l}\text { APRENDIZAGE } \\
\text { ar com o corpo } f\end{array}$ & as diversific & Is de expressão de & $\begin{array}{l}\text { lentos, sensações e } \\
\text { atro, música. } \\
\text { eiras e jogos, escuta }\end{array}$ \\
\hline
\end{tabular}

Fonte: Planos de Ensino dos Professores.

Entre as atividades sugeridas diante desses objetivos, observou-se uma de movimento corporal (Ciranda dos Bichos) utilizando-se a dança a partir da imitação conforme a música. As crianças deveriam imitar os animais citados na letra e expressar-se de acordo com os movimentos.

Outra atividade relacionada à dança foi a partir de atividades de equilíbrio, em que as crianças deveriam equilibrar uma garrafa pet pequena, com um pouco de água e movimentar-se, andando e abaixando-se, sempre tentando evitar que a garrafa caísse. Na sequência, a atividade sugeria, que em comemoração ao Dia da Consciência Negra, as meninas realizariam a Dança do Chorado. Utilizando um arquinho na cabeça com uma garrafa pet presa no arquinho, realizando os movimentos da dança. As mulheres de Vila Bela da Santíssima Trindade, em Mato Grosso, realizam essa dança.

Surgida no Período Colonial, a Dança do Chorado leva esse nome representando o choro dos negros escravos para seus senhores para que os perdoassem dos castigos impostos aos transgressores. O ritmo da música é afro, com marcações em palmas, mesa, banco ou tambor. Realizada apenas por mulheres acompanhadas por dois ou três homens que tocam os instrumentos, com o passar dos tempos passou a ser feita ao final da festa de São Benedito pelas mulheres que trabalharam na cozinha. Atualmente, seu significado é demonstrar, a partir do equilíbrio da garrafa, que as dançarinas, apesar de se encontrarem ao final da festa, continuam sóbrias.

Em relação às danças regionais, na maioria das escolas de Educação Básica de Cuiabá, são realizados eventos culturais em datas comemorativas que promovem a participação das crianças da Educação Infantil, reproduzindo movimentos típicos dessas danças originárias das culturas afro e indígena. A cultura cuiabana também é representada nas escolas pelas danças do Siriri, do Lambadão e Rasqueado Cuiabano. Muitas crianças que participam dessas apresentações já possuem contato com essa cultura a partir da família ou comunidade onde se inserem. 
Nesse sentido, as atividades com a dança na Educação Infantil estão contempladas nos planos de ensino dos professores a partir, principalmente, de datas comemorativas, de acordo com as especificidades de cada comemoração, como danças regionais e/ou expressivas da cultura afrodescendente e indígena.

Em outros aspectos, alguns professores desenvolvem atividades com danças circulares, brincadeiras de roda e demais atividades com os movimentos solicitados pela música ou de forma livre. Entretanto, detém-se, das análises dos planejamentos diários, uma predominância nas atividades que envolvem o movimento a partir do desenvolvimento da lateralidade, equilíbrio e coordenação motora por meio de brincadeiras em circuitos, corridas, obstáculos e saltos.

$\mathrm{Na} \mathrm{BNCC}$, a dança escolar é apresentada como componente curricular da área de linguagem, inserida dentro da disciplina de EF dentre os 06 eixos estruturantes que a compõem: ginástica, jogos e brincadeiras, lutas, danças, esportes e práticas corporais de aventura (BRASIL, 2017).

Nessa perspectiva, a dança constitui-se em uma forma de educação. Segundo Steinhilber (2000, p. 08), "Uma criança que participa de aulas de dança [...] se adapta melhor aos colegas e encontra mais facilidade no processo de alfabetização". Na mesma direção, Cintra (2007, p. 15) pondera que:

A dança tem um papel essencial enquanto atividade pedagógica e favorece o despertar de um vínculo concreto de sujeito-mundo nas crianças, permite o desenvolvimento de atividades que motivam a produção de ação e compreensão, beneficiando o estímulo para ação e decisão no desenrolar das mesmas, fortalecendo a autoestima, a autoimagem, a autoconfiança e o autoconceito da criança.

Dessa forma, a reflexão nos remete ao que afirmam Barilli e Cintra (2013, p. 26.088) que "O ensino de dança na escola não deve se concentrar na formação de futuros bailarinos, deve ajudar no desenvolvimento de suas expressões e suas possibilidades de comunicação e desenvolvimento". Nesse sentido, a dança surge como possibilidade de expressão, de socialização, cooperação, de aprendizagem e desenvolvimento da criatividade (SCARPATO, 2001).

Assim sendo, a utilização da dança no desenvolvimento infantil pressupõe o envolvimento do educador, que precisa se conectar com os benefícios da dança, interagindo com seus educandos na sincronia dos movimentos e na livre expressão corporal.

\section{Considerações finais}

Constatando que as mudanças ocorridas em todo território brasileiro nas últimas décadas trouxeram significativas alterações tanto ao meio prático quanto nas concepções que regem o sistema educacional, concordamos que, com as mudanças estruturais fizeram-se necessárias mudanças políticas em âmbito educacional, com a busca por uma abordagem mais sistêmica para a educação, onde a formação da pessoa humana tornouse umas das prioridades do novo momento vivido.

Esses intensos debates que permearam e ainda fazem parte dos alicerces que se vivenciam atualmente, trazidos pela Constituição Federal, com a consolidação da LDB 
(1996) em suas diversas versões e demais normativas, fizeram compreender a educação como uma totalidade, admitindo que ela ultrapasse o espaço escolar, tendo na emancipação humana uma das suas principais atuações.

Nesse cenário a disciplina de EF teve seu processo histórico de construção e afirmação iniciado no século XIX nas escolas da corte no período histórico imperial do país. Atualmente, devido às visões mais democráticas e humanizadas das concepções e das práticas pedagógicas, foi sendo incorporada gradativamente como componente normativo curricular obrigatório dentro do ciclo de formação humana em seus diversos níveis e/ou etapas de ensino. Saindo de uma perspectiva centrada apenas nos aspectos biológicos do desenvolvimento humano a partir dos esportes de alto rendimento, a EF passa a ser uma disciplina com objetivos que implicam uma dinâmica inclusiva que contemple as dimensões afetivas, sociais, culturais e cognitivas dos alunos nos espaços educativos.

No mesmo direcionamento, o Município de Cuiabá/MT, por meio de suas políticas públicas educativas, ressalta o processo da sistematização do conhecimento e com isso a possibilidade de criar práticas pedagógicas comprometidas na formação de sujeitos capazes de interagir e transformar seu meio social, tendo na escola um espaço de superação.

Embora a realidade das redes educacionais em diversas regiões do país apresente heterogeneidade quanto aos modelos operacionais, Cuiabá vem demonstrando seu grau de comprometimento pela qualidade e efetivação da democracia educacional diante das propostas da BNCC (2017) em suas Políticas Públicas Educacionais, representadas pelas orientações no Ebook Escola Cuiabana (2019). Em consonância com as Propostas Educacionais Nacionais, a Escola Cuiabana apresenta, para e EF na Educação Infantil, proposições de acordo com os Eixos Norteadores e os Campos de Experiência, onde a dança surge como possibilidade de trabalho no campo Corpo, Gestos e Movimentos.

No entanto, tanto as Políticas Públicas Municipais quanto os Projetos Políticos Pedagógicos das Unidades de Ensino, que atendem a Educação Infantil analisados, não dispõem de espaço para que a dança, ou demais conteúdos e abordagens metodológicas da EF sejam referenciados. Essa relação fica a encargo dos educadores, quando da elaboração dos seus planejamentos anuais, bimestrais ou diários.

$\mathrm{Na}$ análise, os planejamentos bimestrais apreciados indicaram algumas atividades referentes ao uso da dança. No entanto, constatou-se a predominância de abordagens que envolvem o movimento a partir de atividades que priorizam desafios de equilíbrio, obstáculos, correr, saltar e cumprir circuitos por meio de jogos e brincadeiras. As dinâmicas com a dança são realizadas de forma intermitente, estando essa abordagem mais relacionada a apresentações em datas comemorativas. No contexto da rede municipal de Educação de Cuiabá, a disciplina de EF tem nas danças regionais um dos seus aportes, que diante das relações conceituais e implicações pedagógicas, acabam por transformar cada escola em um polo cultural.

Nessa perspectiva, a abordagem é interessante, no sentido de que valoriza a cultura local e regional no contexto social do estudante, sendo essa uma característica marcante das propostas educacionais do município. Entretanto, vale ressaltar que o objetivo principal nesse caso, é a estética da reprodução dos movimentos da dança para apreciação da comunidade escolar, e não a utilização da dança como uma abordagem pedagógica que auxilie a aprendizagem a partir da interação entre movimento/expressões corporais e desenvolvimento cognitivo. 
Portanto, embora o espaço da disciplina de EF na Rede Municipal de Ensino de Cuiabá encontre-se alicerçado nas experiências vivenciadas pelos profissionais e na interação com os estudantes e comunidade escolar, apoiado pelas diversas normativas educacionais, vale destacar que é fundamental o entendimento de que o desenvolvimento infantil em sua forma ampla se dá tanto pelos processos biológico-cognitivos quanto pela interação social.

Dessa forma, é imprescindível que as atividades pedagógicas da EF para a Educação Infantil se pautem na relação entre ambiente, cultura e conhecimento. Nesse contexto, a dimensão do movimento na integração corpo e mente por meio da dança corrobora mediando o processo da construção do pensamento, bem como das habilidades espaciais e motoras e demais competências relevantes ao desenvolvimento infantil.

Sem pretensão de esgotar o tema, estima-se que as reflexões aqui dispostas sirvam de parâmetro para discussões posteriores no sentido de se desenvolverem prospectivas de maior inserção de atividades com a dança nas aulas de EF para a Educação Infantil, considerando sua importância no processo de uma aprendizagem significativa, que contemple todas a dimensões do desenvolvimento humano.

\section{REFERÊNCIAS}

ANDRADE, Lucimary Bernabé Pedrosa de; Educação Infantil: Discurso, Legislação e Práticas Institucionais. - São Paulo: Cultura Acadêmica, 2010. 194p.

http://hdl.handle.net/11449/109136 Acesso em 18 jun. 2021.

APOLINARIO, Poliana Cristina Gulhak; GRANDO, Daiane. Dança e ritmo nas aulas de Educação Física. 10 Congresso Norte Paranaense de Educação Física Escolar CONPEF 5 Congresso Nacional de Formação de Professores de Educação Física UEL Londrina - 2021. Disponível em

http://www.uel.br/eventos/conpef/portal/pages/arquivos/2021.pdf Acesso em 30 nov. 2021

\section{BAECKER, I. M. "Identitätsfördrung im Bewegungsunterricht Brasilianischer}

Grundschulen”. 1996. (Doutorado). Tradução Autora. Universidade de Hamburgo, República Federal da Alemanha.

BARILLI, Daniele. CINTRA, Rosana Carla Gonçalves Gomes. Dança na Educação Infantil: uma estratégia pedagógica para a educação sustentável. XI Congresso nacional de Educação-Educere, 2013. Disponível em

https://educere.bruc.com.br/arquivo/pdf2013/13432_6725.pdf. Acesso em 01 dez. 2021.

BARRETO, Débora. Dança... Ensino, sentidos e possibilidades na escola. São Paulo: autores associados, 2008. 161p.

BATISTA, Danielle. Formação Continuada de Professores de Educação Física da Rede Municipal de Ensino de Cuiabá/MT: entre o ideal e o vivido. 255f. Dissertação (Mestrado em Educação).Universidade Federal de Mato Grosso, Cuiabá, 2015. Disponível em: https://bdtd.ibict.br/vufind/Record/UFMT_cf3105b6d2c92eb53d79e7a5bd22bf0d Acesso em 15 set. 2021. 
BRASIL. Constituição da República Federativa do Brasil. Brasília, DF: Senado Federal, 1988.

BRASIL. Estatuto da Criança e do Adolescente. Câmera dos Deputados, Lei nำ 8.069, de 13 de julho de 1990. DOU de 16/07/1990 - ECA. Brasília, DF.

BRASIL. MINISTÉRIO DA EDUCAÇÃO. Base Nacional Comum Curricular. Brasília, 2017. Disponível em: <http://basenacionalcomum.mec.gov.br>. Acesso em: 15 jul. 2021.

BRASIL. MINISTÉRIO DA EDUCAÇÃO E DO DESPORTO. Lei de Diretrizes e Bases da Educação Nacional, Lei no 9394/96. Brasília, 1996.

BRASIL. Referencial Curricular Nacional para Educação Infantil. V. 1. Ministério da Educação e do desporto. Secretaria de Educação Fundamental. Brasília, DF: MEC/SEF, 1998.

BRASIL. CONSELHO NACIONAL DE EDUCAÇÃO. CÂMARA DE EDUCAÇÃO BÁSICA. Resolução n. 5 de 17 de dezembro de 2009. Fixa as Diretrizes Curriculares Nacionais para a Educação Infantil. Brasília, CNE/CEB, 2009.

BRASIL. Ministério da Educação. Secretaria de Educação Básica. Diretrizes Curriculares Nacionais Para a Educação Infantil/Secretaria de Educação Básica Brasília: MEC, SEB, 2010.

BRASIL. Secretaria de Educação Fundamental. Parâmetros Curriculares Nacionais: Educação Física/Secretaria de Educação Fundamental - Brasília: MEC/SEF, 1997, 96p.

BREGOLATO, Roseli Aparecida. A. Cultura Corporal da Dança. 3ª ed. São Paulo: Ícone, 2007.

CHIZOTTI, Antonio. Pesquisa em Ciências Humanas e Sociais. São Paulo: Cortez, 1991.

CINTRA, Dulce Maria Rosa. The inserted of the school dance how a possibility of integral education. $107 \mathrm{f}$. Dissertação (Mestrado em Ciências Humanas) - Universidade do Oeste Paulista, Presidente Prudente, 2007. Disponível em: < http://bdtd.unoeste.br:8080/tede/handle/tede/922> Acesso em: 15 Jun. 2021.

CUIABÁ. Lei no 5871 de 30/09/2014. 2014. Disponível em https://leismunicipais.com.br/lei-organica-cuiaba-mt. Acesso em 22 Jun. 2021.

CUIABÁ, SME/DGE/CTE/CTPO. Referencial teórico-metodológico para (re)elaboração do Projeto Político Pedagógico na perspectiva da Escola Cuiabana. 2021.

DAMÁSIO, António Rosa. O Sentimento de Si: O Corpo, a Emoção e a Neurobiologia da Consciência. 5ed. Mira-Cintra: Europa-América. 2000.

DELORS, Jacques. Educação: Um tesouro a descobrir. Relatório para a UNESCO da Comissão Internacional sobre a Educação para o século XXI. Rio Tinto: Asa, 1996. 
ESCOLA CUIABANA: cultura, tempos de vida, direitos de aprendizagem e inclusão./ Edilene de Souza Machado e Mabel Strobel Moreira da Silva (organizadoras). $1^{\text {a }}$ edição. Cuiabá-MT: Print Gráfica e Editora, 2019.

ESCOLA, EMEB Maria Tomich Monteiro da Silva. Projeto Político Pedagógico, 2021.

FACHIN, Odilia. Fundamentos de metodologia. 4. ed. São Paulo: Saraiva, 2006.

FLICK, Uwe. Introdução à pesquisa qualitativa. 3. ed. Porto Alegre: Artmed, 2009.

KÖCHE, José Carlos. Fundamentos de metodologia científica: teoria da ciência e prática da pesquisa. 23. ed. Petrópolis: Vozes, 2006.

LÜDKE, Menga.; ANDRÉ, Marli. Pesquisa em educação: abordagens qualitativas. São Paulo: EPU, 2003.

MACHADO, Edilene de Souza.; SILVA, Mabel Strobel Moreira da. Escola Cuiabana: cultura, tempos de vida, direitos de aprendizagem e inclusão. $1^{1}$ a edição. Cuiabá-MT: Print Gráfica e Editora, 2019. 256p

MARTINS, Gilberto de Andrade.; THEOPHILO, Carlos Renato. Metodologia da investigação científica para ciências sociais aplicadas. São Paulo: Atlas, 2007.

MATO GROSSO. Secretaria de Estado de Educação. Documento de Referência Curricular para Educação Infantil de Mato Grosso. Cuiabá: Gráfica Print, 2018. 76p.

MATO GROSSO. Secretaria de Estado de Educação. Orientações Curriculares: Concepções para a Educação Básica/Secretaria de Estado de Educação e Mato Grosso. Cuiabá: Gráfica Print, 2012. 128p.

MATO GROSSO. Secretaria de Estado de Educação. Normas Legais Para Os Dirigentes Empreendedores/Superintendência de Gestão Escolar. 2004. 453p.

MINAYO, Maria Cecília de Souza (org.). Pesquisa Social. Teoria, método e criatividade. 34 ed. Petrópolis: Vozes, 2014.

NANNI, Dionísia. Dança-Educação: pré-escola à universidade. Rio de Janeiro: Sprint, 1995.

PINTADO, Sheila. Bienestar emocional, imagem corporal, autoestima y sexualidad em mujeres com cancer de mama. 2009. Dialnet, v. 233. (Doutorado em Psicologia). Universidade de Valência, Valencia 2013.

SACRISTÁN, José. Gimeno; PÉREZ GÓMEZ, Angel. Compreender e transformar o

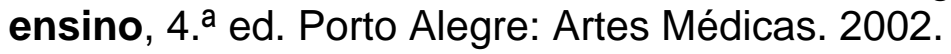

SANTO, Loredana Patricia Espirito; FERNANDES, Cleonice Terezinha; MACIEL, Cilene Maria Lima Antunes; REIS Filho, Adilson. As contribuições da dança no desenvolvimento motor de crianças da educação infantil. Arquivos em Movimento, v. 11, n.2, p. 20-46, 
2015. Disponível em:<https://revistas.ufrj.br/index.php/am/article/view/9257/pdf_59> Acesso em: 07 jul. 2021.

SILVA, Gabriel Gomes de Souza.; MACIEL, Cilene Maria Lima Antunes; FERNANDES, Cleonice Terezinha.; FONTES, Tania Aparecida de Oliveira. As contribuições da dança (do ventre) no ensino-aprendizagem para crianças: uma óptica neurocientífica. Educação Pública, v. 20, n.4, 2020. Disponível em:

https://educacaopublica.cecierj.edu.br/artigos/20/4/as-contribuicoes-da-danca-do-ventreno-ensino-aprendizagem-para-criancas-uma-optica-neurocientifica> Acesso em: 08 jun. 2021.

SOARES, Andressa et. al. Improvisação e dança: conteúdo para a dança na educação física. Florianópolis: UFSC, 1998.

SCARPATO. Marta Thiago. Dança Educativa: um fato em escolas de São Paulo. Caderno CEDES, Campinas, SP, v.21, n.53, p.57-68; 2001.

SCHWARTS, Gisele Maria. Linguagem Corporal de Expressão Da Criatividade e Seu (Des) Envolvimento na Educação Física. Motriz, v. 3, n. 2, 1997.

STEINHIBER, Jorge. Dança para acabar com a discussão. Conselho Federal de Educação Física- CONFEF, Rio de Janeiro, n. 5, nov/dez. 2000.

TRIGUEIRO, Rodrigo de Menezes. RICIERI, Marilucia. FREGONEZE, Gisleine Bartolomei. BOTELHO Joacy; Metodologia Científica. - Londrina: Editora e Distribuidora Educacional S.A., 2014. 184 p.

Recebido em: 16 de setembro de 2021. Aceito em: 10 de dezembro de 2021. Publicado em: 05 de janeiro de 2022. 